Pseudosphärische, Hyperbolisch-Sphärische und Elliptisch-Sphärische Geometrie. By F. Schilling. Leipzig and Berlin, Teubner, 1937. viii +240 pp.

The writer of this review has previously reported on several of Professor Schilling's works for the Bulletin, see for instance vol. 38 (1932), p. 335. The present volume is a further elaboration of the Pseudo-sphere and non-euclidean geometry, with the purpose of making this fascinating subject even more attractive to the ordinary trained teacher and student than in the preceding volumes.

In this task Professor Schilling, of the Technische Hochschule of Danzig, has succeeded admirably and I can repeat in praise only what I have said in my previous reviews.

\title{
ARNOLD EMCH
}

L'Emploi des Observations Statistiques. Méthodes d'Estimation. By G. Darmois. (Actualités Scientifiques et Industrielles, No. 356; Statistique Mathématique, exposés publiés sous la direction de Georges Darmois, I.) Paris, Hermann, 1936. 29 pp.

The first part of this booket deals with problems of estimating unknown parameters of frequency distributions from $n$ observations by finding a point in the space of the parameters by the use of a point in the space of the observations, thus giving the best information concerning the position of the "true point."

Part two presents definitions of the distance of an estimation from the true value, and limits of estimations. Comparisons are made of precisions of laws for the mean and median for certain probability laws, together with a comparison of the standard errors of the mean deviation and the standard deviations. The importance of the ratios of two standard deviations is shown.

The next section gives a geometric meaning of the maximum of the function of points in the parametric and observational spaces and shows how to determine the principal part of the standard deviation of an estimation of a parameter which furnishes the maximum of this function. The maximum of this function is compared with R. A. Fisher's maximum of likelihood. The geometric interpretation is very interesting.

The last part defines exhaustive estimation which is equivalent to R. A. Fisher's sufficient estimation. Comparisons are made of two estimations of an unknown parameter by means of the sizes of standard deviations. The quantity $g=E[\partial \log f / \partial m]^{2}$, plays an important role in the last two sections; $f$ is a frequency function.

\section{W. D. BATEN}

Méthode des Caractéristiques pour l'Intégration des Équations aux Dérivées Partielles Linéaires Hyperboliques. By Mlle. Hélène Freda. (Mémorial des Sciences Mathématiques, Fascicule LXXXIV.) Paris, Gauthier-Villars, 1937. $7+82 \mathrm{pp}$.

The following list of chapter titles gives a good notion of what to expect from this pamphlet: Preface de V. Volterra; Chapitre I. Equations hyperboliques: problèmes aux limites et variétés caractéristiques; Chapitre II. Inté- 